\title{
Specificity of the failure to inhibit responses in overweight children
}

Citation for published version (APA):

Nederkoorn, C., Coelho, J. S., Guerrieri, R., Houben, K., \& Jansen, A. (2012). Specificity of the failure to inhibit responses in overweight children. Appetite, 59, 409-413.

https://doi.org/10.1016/j.appet.2012.05.028

Document status and date:

Published: 01/01/2012

DOI:

10.1016/j.appet.2012.05.028

Document Version:

Publisher's PDF, also known as Version of record

Document license:

Taverne

Please check the document version of this publication:

- A submitted manuscript is the version of the article upon submission and before peer-review. There can be important differences between the submitted version and the official published version of record.

People interested in the research are advised to contact the author for the final version of the publication, or visit the DOI to the publisher's website.

- The final author version and the galley proof are versions of the publication after peer review.

- The final published version features the final layout of the paper including the volume, issue and page numbers.

Link to publication

\footnotetext{
General rights rights.

- You may freely distribute the URL identifying the publication in the public portal. please follow below link for the End User Agreement:

www.umlib.nl/taverne-license

Take down policy

If you believe that this document breaches copyright please contact us at:

repository@maastrichtuniversity.nl

providing details and we will investigate your claim.
}

Copyright and moral rights for the publications made accessible in the public portal are retained by the authors and/or other copyright owners and it is a condition of accessing publications that users recognise and abide by the legal requirements associated with these

- Users may download and print one copy of any publication from the public portal for the purpose of private study or research.

- You may not further distribute the material or use it for any profit-making activity or commercial gain

If the publication is distributed under the terms of Article $25 \mathrm{fa}$ of the Dutch Copyright Act, indicated by the "Taverne" license above, 
Research report

\title{
Specificity of the failure to inhibit responses in overweight children
}

\author{
Chantal Nederkoorn ${ }^{a, *}$, Jennifer S. Coelho ${ }^{\text {b,c }}$, Ramona Guerrieri ${ }^{\text {a }}$, Katrijn Houben ${ }^{\text {a }}$, Anita Jansen ${ }^{\text {a }}$ \\ ${ }^{a}$ Faculty of Psychology and Neuroscience, Maastricht University, Maastricht, The Netherlands \\ ${ }^{b}$ Eating Disorders Program, Douglas University Institute in Mental Health, Verdun, Quebec, Canada \\ ${ }^{\mathrm{c}}$ Department of Psychiatry, McGill University, Montreal, Quebec, Canada
}

\section{A R T I C L E I N F O}

Article history:

Received 20 April 2012

Received in revised form 23 May 2012

Accepted 27 May 2012

Available online 1 June 2012

Keywords:

Impulsivity

Self-control

Exposure

Specificity

Obesity

Food cue

\begin{abstract}
A B S T R A C T
Poor response inhibition has been associated with obesity, excessive food intake, and other consumptive behaviours, including alcohol use. However, the correlation between obesity and addictive behaviours like alcoholism is low: people who are obese appear to have a specific problem in restraining food intake. This would imply that obese people have more difficulties in inhibiting responses towards food, compared to other rewarding stimuli. In the present study 89 children (ages 7-9) were tested with the stop signal task, in which responses towards food pictures or toy pictures had to be inhibited. Results showed that children were less effective in inhibiting responses towards food and percentage overweight predicted a lower ability to inhibit responses in general. When dichotomizing the sample in overweight and lean children, it appeared that overweight children were specifically less effective in inhibition towards food cues, compared to lean children. In conclusion: The results confirm weight related inhibitory problems and might explain the increased overeating to food cues in overweight children, as reported in the literature.
\end{abstract}

(c) 2012 Elsevier Ltd. All rights reserved.

\section{Introduction}

In Western societies, palatable calorically dense food is omnipresent and relatively cheap compared to healthier foods (Drewnowski \& Darmon, 2005). Whereas people used to struggle to obtain enough calories and nutrients, currently a substantial part of the population is struggling to restrict their intake, specifically of energy dense foods. In combating appetite, people need to make an appeal to their self-control (Lowe, 2003). This makes people with less effective self-control vulnerable for overeating and unhealthy weight gain. Research indeed shows that obese people have less effective inhibitory control, compared to those who are lean (Nederkoorn, Havermans, Roefs, Smulders, \& Jansen, 2006). Moreover; inhibitory control predicts increased food intake: people with less effective response inhibition eat more during a taste test with palatable, energy dense foods than do people with effective response inhibition (Guerrieri et al., 2007). Not only in adults, but also overweight/obese children and adolescents score lower on tasks measuring inhibitory control and executive functioning (Batterink, Yokum, \& Stice, 2010; Cserjési, Luminet, Molnár, \& Lénárd, 2007; Nederkoorn, Braet, Van Eijs, Tanghe, \& Jansen, 2006; Verbeken, Braet, Claus, Nederkoorn, \& Oosterlaan, 2009; Verdejo-García et al., 2010). Self-regulatory skills in toddlers 2 years of age even predicted overweight and obesity at 5.5 years of age (Graziano, Calkins, \& Keane, 2010).

\footnotetext{
* Corresponding author.

E-mail address: c.nederkoorn@maastrichtuniversity.nl (C. Nederkoorn).
}

It seems conceivable that the same lack of inhibitory control would make children vulnerable to other appetitive, rewarding behaviour. Indeed, response inhibition predicts a variety of consumptive behaviours in children and adolescents, including alcohol and tobacco use (Nigg et al., 2006; Riggs, Spruijt-Metz, Chou, \& Pentz, 2011). Strangely, the correlation between obesity and other addictive behaviours is often low (Riggs et al., 2011), absent or even negative (Kleiner et al., 2004; Mather, Cox, Enns, \& Sareen, 2008). Although ineffective inhibitory control underlies different types of excessive consumption, people who are obese specifically fail in resisting responses towards food and not so much towards other stimuli. Possibly, they acquired conditioned responses to food cues, which are in turn associated with increased food intake. When people are confronted with stimuli that predict food intake, they show cephalic phase responses, including increases in salivation and gastric activity (Nederkoorn, Smulders, \& Jansen, 2000; Power \& Schulkin, 2008). These responses allow for larger subsequent intake (Mattes, 1997).

Although individuals who are within the normal-weight range exhibit such conditioned food responses (e.g., Cornell, Rodin, \& Weingarten, 1989), it appears that obesity in particular is associated with increased appetitive responding to food cues. For example, individuals who are obese show increased salivary response and craving after exposure to food cues, compared to those who are lean (Ferriday \& Brunstrom, 2011; Wooley, Wooley, \& Woods, 1975). Similarly, children who are obese tend to eat somewhat more after exposure to food cues than do those who are of healthy weight (Jansen et al., 2003). The increased responsivity of those 
who are obese also extends to attention to food-related cues, with children who are obese demonstrating more alertness to food adverts than the lean children (Halford, Gillespie, Brown, Pontin, \& Dovey, 2004), and adults who are obese showing increased attention for food cues relative to lean participants (Castellanos et al., 2009; Werthmann et al., 2011).

An analogous responsiveness is found in drug users when exposed to relevant drug cues (Carter \& Tiffany, 1999; Goldstein \& Volkow, 2002). Goldstein and Volkow (2002) suggest in their model that craving or anticipation of substance use leads to a 'state' of decreased inhibitory control. Thus, exposure to relevant cues might not only induce cephalic phase responses, but also lessen inhibitory control. It seems therefore plausible that people who are obese are worse at inhibiting responses towards palatable food cues, compared to non-food cues. To our knowledge, this has not been tested yet; it has only been shown that people who are obese have less capacity to inhibit responses towards neutral stimuli than do individuals who are lean. The responsivity to food-related cues appears to follow the same pattern in both adults and children. The current study focused on children because overweight children have an increased risk of being obese as adults (Dietz, 1995), suggesting that the development of early interventions, and increased insight into children's food-related cue reactivity, are a priority for public health. Inhibition towards food and toy pictures, both with positive valence, was tested. It was hypothesized that a higher BMI would be related to less inhibitory control, especially towards food. In addition, it was expected that the effects would be more pronounced when dividing the children in clinically relevant weight groups.

\section{Methods}

\section{Participants}

Children were recruited from two elementary schools. All parents of children in grades 4 and 5 were sent an information letter, and children who returned a consent form signed by a parent were asked to participate. A total of 91 children were tested, aged 7-9. Two children were excluded because of technical problems. Data were checked for outliers, but all dependent measures were within 3 SD from the mean.

Percentage overweight was calculated by dividing BMI (measured at the end of the experiment) by the national norm BMI (Van Winckel \& van Mil, 2001), adjusted for gender and age, $\times 100$. Fourteen children (11 girls, 3 boys) were classified as overweight (i.e., they were more than $120 \%$ overweight); the remaining 75 children (37 boys, 38 girls) were classified as lean. Descriptives are presented in Table 1 . The percentage of children who were overweight in the present sample (15.7\%) is normal in the Netherlands, in which around $16 \%$ of children are overweight (van den Hurk, van Dommelen, van Buuren, Verkerk, \& HiraSing, 2007).

\section{Measures}

Response inhibition was measured by an adapted version of the Stop signal task (Logan \& Cowan, 1984). This task involves a go and stop task. The go task was a choice reaction time task in which participants had to decide as quickly as possible whether a picture was on the left or right side of the computer screen, by pressing a corresponding button. In $25 \%$ of the trials (the stop trials) an auditory stop signal $(1000 \mathrm{~Hz}, 100 \mathrm{~ms})$ was presented, indicating that participants had to inhibit their response. Initially, the stop signal delay was set at $250 \mathrm{~ms}$ after the presentation of the go signal and then adjusted dynamically depending on participants' responses.

The two variables measured in this task are the reaction time (RT) and the stop delay. To calculate the stop signal reaction time (SSRT) the following procedure was used (Scheres et al., 2003): First, all reaction times on the go trials of a participant were rank ordered, from fastest to slowest; second, the nth percentage reaction time was picked, $\mathrm{n}$ being defined by the probability of responding given a stop signal; finally, the average stop signal interval was subtracted from this reaction time to estimate SSRT. Higher SSRTs reflect less effective response inhibition.

Two adjustments were made. First, 10 pictures of highly palatable food (e.g., candy, chocolate) were used in the food condition whereas the toy condition consisted of 10 pictures of attractive toys (e.g., pencils, wrapped presents). Neutral pictures were used in the practice sessions. The food and toy pictures were carefully matched on colour and shape, to make them equally visually attractive (see Fig. 1). Furthermore, children could earn points during the tasks. In the food condition, children could earn "candy points", which they could exchange for real candy afterwards. In the toy condition, children could earn "toy points" which could be exchanged for small presents, like a pencil. With every correct and fast response (faster than their own mean response during the practice trials $+100 \mathrm{~ms}$ ), 1 point could be earned. During the stop trials, failure to inhibit responses cost 2 points. Children always started with 10 points. The food and toy condition both consisted of 64 trials, in counterbalanced order.

Hunger was measured on a $10 \mathrm{~cm}$ VAS scale, ranging from not at all to very hungry. Children were explained individually what a score meant and shown two examples of scoring when feeling very hungry and feeling not at all hungry.

\section{Procedure}

Children were tested individually. First, hunger was measured. Next, the stop task was performed. Finally, weight and height were measured (without shoes) and children received a small present (they were allowed to choose two small toys, like a pencil or gum and two small sweets. They were told they earned this gift during the task, but in fact every child received the same rewards). We certify that all applicable institutional and governmental regulations concerning the ethical use of human volunteers were followed during this research. Approval of the Ethical Committee of the Faculty of Psychology and Neuroscience, Maastricht University was obtained.

\section{Analyses}

In the first ANOVA for repeated measures, condition (food vs. toy) was entered as a within-subjects variable, gender was entered

Table 1

Participant characteristics and statistical tests of group differences.

\begin{tabular}{|c|c|c|c|}
\hline & Lean children & Overweight children & \\
\hline BMI & $16.1(1.5)$ & $21.1(2.7)$ & $t(87)=6.9, p<0.001$ \\
\hline \% Overweight & $100.6(8.8)$ & $132.9(16.7)$ & $t(87)=7.1, p<0.001$ \\
\hline Age & $8.1(0.8)$ & $8.1(.83)$ & $t(87)=0.2, p=0.83$ \\
\hline Gender & 37 boys, 38 girls & 3 boys, 11 girls & Pearson Chi-Square $=3.7, p=0.054$ \\
\hline Hunger & $4.4(2.7)$ & $4.2(2.4)$ & $t(87)=0.2, p=0.84$ \\
\hline
\end{tabular}




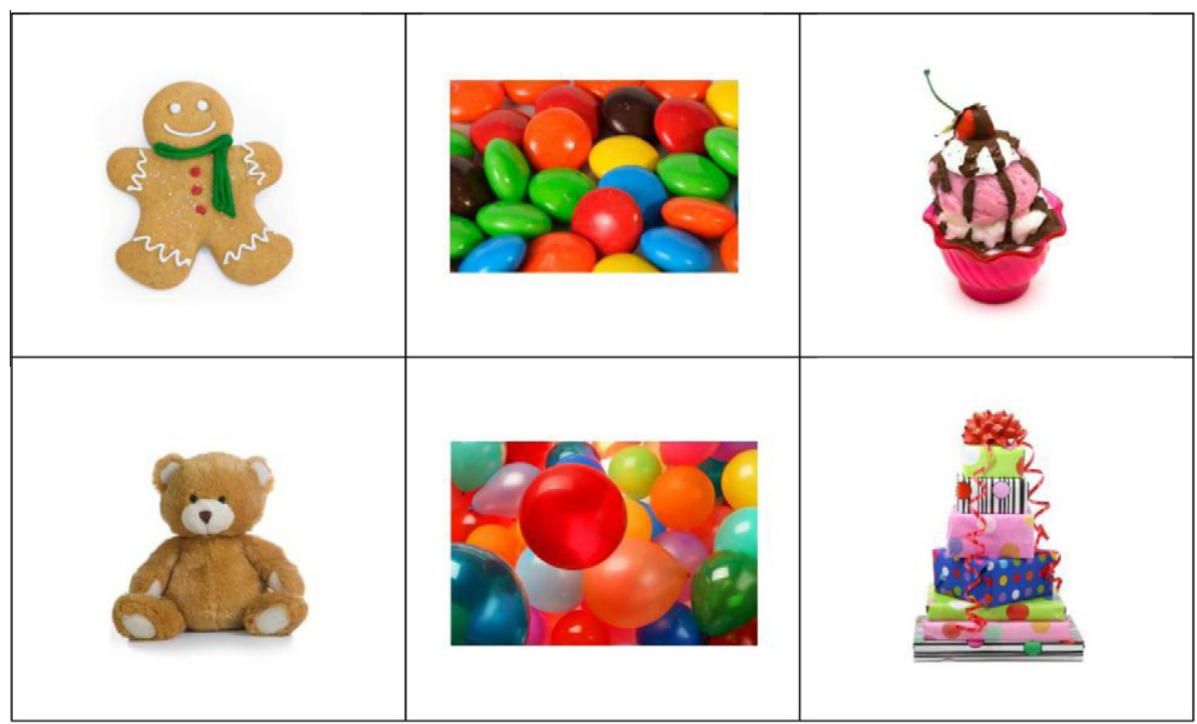

Fig. 1. Three pairs of food and toy pictures.

as between-subjects variable and percentage overweight and hunger as covariates. In the model, the interaction between condition and percentage overweight was analysed. Inhibitory control, as measured by SSRT, was the dependent variable. In the second ANOVA for repeated measures, overweight was not entered as continuous variable, but group (overweight vs. lean) was entered as a between subject variable. The other variables were equal to the first ANOVA.

\section{Results}

When overweight was entered as a continuous measure, there appeared no influence of hunger or gender on overall inhibition, as measured with SSRT (hunger: $F(1,85)=0.89, \quad p=0.35$, $\eta_{\mathrm{p}}{ }^{2}=0.01$; gender: $\left.F(1,85)=1.1, p=0.3, \eta_{\mathrm{p}}{ }^{2}=0.01\right)$. Overweight had a significant effect on overall inhibition $(F(1,85)=4.3$, $\left.p=0.041, \eta_{p}{ }^{2}=0.05\right)$ : children with a higher percentage of overweight performed less well on the stop signal task. When looking at the difference between the food and toy condition, it appeared that overall, children were more effective in response inhibition in the toy condition then in the food condition $(F(1,85)=11.0$, $p<0.01, \eta_{p}{ }^{2}=0.12$; mean SSRT 241.7 vs. $276.0,95 \%$ CI of the difference between toy and food condition $=13.7-55.0 \mathrm{~ms}$ ). The interaction between overweight and condition appeared not significant $\left(F(1,85)=0.08, p=0.79, \eta_{\mathrm{p}}{ }^{2}=0.001\right)$.

When the same analyses was repeated, with children classified as overweight or lean, again no effects of hunger or gender were found (hunger: $F(1,85)=0.79, \quad p=0.38, \quad \eta_{\mathrm{p}}^{2}=0.01$; gender: $\left.F(1,85)=1.7, p=0.2, \eta_{p}^{2}=0.02\right)$. Overweight children appeared marginally significantly less effective in response inhibition compared to those who were lean $(F(1,85)=3.9, \quad p=0.051$, $\eta_{\mathrm{p}}{ }^{2}=0.044$; mean SSRT $=301.1$ vs. $251.3,95 \% \mathrm{CI}$ of the difference between overweight and lean $=-0.2$ to $99.7 \mathrm{~ms}$ ). Again, children were more effective in response inhibition in the toy condition then in the food condition $\left(F(1,85)=14.1, p<0.001, \eta_{\mathrm{p}}{ }^{2}=0.14\right)$; however, both main effects were qualified by an interaction between condition and group $\left(F(1,85)=3.9, p=0.049, \eta_{p}{ }^{2}=0.05\right)$. Children who were overweight were particularly ineffective at inhibiting their responses towards food stimuli (see Fig. 2). Follow-up tests demonstrated significant group differences in the food condition, with children who were overweight less able to inhibit their responses towards food pictures than those who were lean $\left(F(1,85)=6.2, p=0.015, \eta_{\mathrm{p}}{ }^{2}=0.07 ;\right.$ mean SSRT 342.2 vs. 264.2, $95 \% \mathrm{CI}$ of the difference between overweight and lean $=8.2-130.7 \mathrm{~ms})$. No group differences emerged in the toy condition $\left(F(1,85)=0.68, p=0.41, \eta_{\mathrm{p}}{ }^{2}=0.01\right.$; mean SSRT 259.8 vs. $238.4,95 \% \mathrm{CI}$ of the difference between overweight and lean $=-34.3$ to $66.9 \mathrm{~ms}$ ).

\section{Discussion}

It was hypothesized that overweight in children would be related to inhibitory control. In addition, it was hypothesized that children with more overweight would have more difficulties in inhibiting responses towards food stimuli then towards toy stimuli. As expected, we found that in our sample of 7-9 year old children, overweight was related to overall more difficulties with response inhibition. This is in line with previous findings (e.g., Nederkoorn, Braet et al., 2006; Verbeken et al., 2009). The capacity to inhibit responses towards food or toy stimuli did not interact with percentage overweight over the whole group. However, when

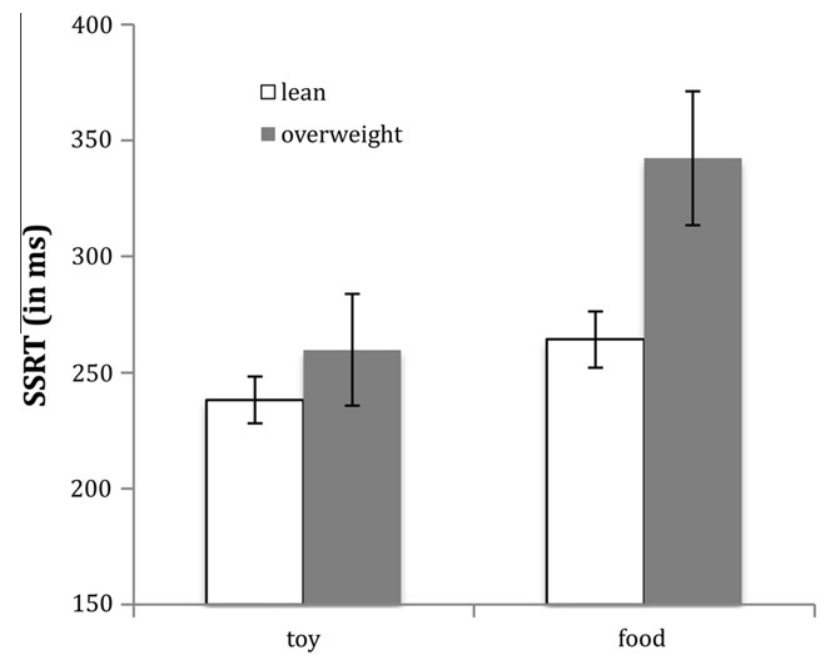

Fig. 2. Inhibitory control, measured by stop signal reaction times, by condition (food and toy) and group (overweight and lean). Error bars indicate standard errors of the mean. 
dividing the group in an overweight and lean group, making more clinical relevant groups, it appeared that the overweight children were less able to inhibit their responses towards food stimuli than were lean children. This supports the specificity of inhibition problems associated with being overweight and is in line with Goldstein and Volkow (2002), who hypothesized that exposure to relevant cues would decrease inhibition, making people more vulnerable for responding to temptations. The cognitive-processing model of Tiffany (Tiffany \& Conklin, 2000) states that craving requires mental effort, and therefore may interfere with cognitively-demanding tasks. The food pictures might have induced craving particularly in the overweight sample, and therefore diminished subsequent task performance. Unfortunately, craving was not measured in the current study, making it impossible to test if craving acted as a mediator of the effect. In the literature, some studies confirm that exposure to food cues reduces executive functioning (e.g., visuospatial working memory; Tiggemann, Kemps, \& Parnell, 2010), whereas others found no effect on response inhibition (Nederkoorn, Van Eijs, \& Jansen, 2004). However, these studies measured processing of neutral stimuli, in the presence of food exposure. In the present study, it was shown that specifically inhibition towards food stimuli was less effective in children who were overweight, compared to the lean sample.

This failure in response inhibition after exposure to food pictures might offer perspectives for training or treatment. Recent studies found that specific training of inhibition to food cues could help reduce consumption of high-caloric food (Houben, 2011; Houben \& Jansen, 2011). In these studies, participants learned to inhibit responses towards a specific stimulus (e.g., chocolate) and to respond towards different stimuli (e.g., empty plates). For instance, they always had to press (go) when a picture on the computer screen is in landscape and inhibit their response (no-go) when the picture is in portrait view. The orientation of the picture is therefore the relevant feature, while the content is irrelevant. However, by manipulating the content of the pictures, the participant could learn to inhibit responses towards specific stimuli, without explicit awareness. Results showed that the manipulation effectively decreased preference and intake of the high-caloric food. Although long-term benefits still need to be established, this type of training appears promising.

Besides bolstering resistance to temptations in the environment, the environment could be adjusted to decrease temptation. Commercials and advertisements for palatable food effectively increase intake (Halford et al., 2004) and overweight children might be especially responsive to these cues. Restriction or regulation of advertisements and commercials of high-caloric foods, especially aimed at children, seems therefore advisable. Some jurisdictions have already implemented regulation to this effect, with promising results. For example, in Quebec, marketing for food or toys aimed at children under age 13 has been regulated for over 30 years, with recent reports suggesting that this ban decreased the tendency to buy fast food by 13 percent (Dhar \& Baylis, 2011). The laws of many jurisdictions have focused on any advertisements targeted at children (that is, not just food-related advertisements, but any advertising targeted at young children in general). However, the results of the current study suggest that food-related advertisements may be particularly deleterious to the obesity epidemic, given that children who are already overweight may be differentially susceptible to these advertisements (but not to attractive items in general, like toys).

The failure to replicate reduced general inhibition in children who were overweight might be due to a lack of power, due to the small sample size in the present study. However, this would suggest that the effect size for general inhibition, if it exists, is smaller than the effect size of inhibition towards food stimuli. Alternatively, it is possible that overweight children do differ from lean children in inhibition towards neutral stimuli, but not towards (non-food-related) positive stimuli, like the toy stimuli used in the present study. In addition, in the present study children could earn points. Possibly, the overweight children were motivated more by this reward compared to the lean children, resulting in a smaller difference between the two groups. The small sample of children who were overweight also diminishes the external validity. A replication with a larger sample size, especially of children who are overweight, is therefore warranted.

In conclusion, the present study shows that children who are overweight are less effective in inhibiting their responses towards food cues than are children who are within the normal-weight range. No general problem in inhibitory control was found. These findings might explain the responsiveness of overweight children to food cues.

\section{References}

Batterink, L., Yokum, S., \& Stice, E. (2010). Body mass correlates inversely with inhibitory control in response to food among adolescent girls. An fMRI study. Neuroimage, 52, 1696-1703.

Carter, B. L., \& Tiffany, S. T. (1999). Meta-analysis of cue reactivity in addiction research. Addiction, 94, 327-340.

Castellanos, E. H., Charboneau, E., Dietrich, M. S., Park, S., Bradley, B. P., Mogg, K., et al. (2009). Obese adults have visual attention bias for food cue images: evidence for altered reward system function. International Journal of Obesity, 33, 1063-1073.

Cornell, C. E., Rodin, J., \& Weingarten, H. (1989). Stimulus-induced eating when satiated. Physiology and Behavior, 45, 695-704.

Cserjési, R., Luminet, O., Molnár, D., \& Lénárd, L. (2007). Is there any relationship between obesity and mental flexibility in children? Appetite, 49, 675-678.

Dhar, T., \& Baylis, K. (2011). Fast food consumption and the ban on advertising targeting children. The Québec experience. Journal of Marketing Research, 48, 799-813.

Dietz, W. H. (1995). Childhood obesity. Prevalence and effects. In Kelly D. Brownell \& Christopher G. Fairburn (Eds.), Eating Disorders and Obesity. A Comprehensive Handbook (pp. 400-438). New York: Guilford Press.

Drewnowski, A., \& Darmon, N. (2005). The economics of obesity. Dietary energy density and energy cost. American Journal of Clinical Nutrition, 82(Suppl.), 265S-273S.

Ferriday, D., \& Brunstrom, J. M. (2011). 'I just can't help myself. Effects of food cue exposure in overweight and lean individuals. International Journal of Obesity, 35 $142-149$.

Goldstein, R. Z., \& Volkow, N. D. (2002). Drug addiction and its underlying neurobiological basis. Neuroimaging evidence for the involvement of the frontal cortex. The American Journal of Psychiatry, 159, 1642-1652.

Graziano, P. A., Calkins, S. D., \& Keane, S. P. (2010). Toddler self-regulation skills predict risk for pediatric obesity. International Journal of Obesity, 34, 633-641.

Guerrieri, R., Nederkoorn, C., Stankiewicz, K., Alberts, H., Geschwind, N., Martijn, C., et al. (2007). The influence of trait and state impulsivity on food intake in normal-weight healthy women. Appetite, 49, 66-73.

Halford, J. C. G., Gillespie, J., Brown, V., Pontin, E. E., \& Dovey, T. M. (2004). Effect of television advertisements for foods on food consumption in children. Appetite, 42, 221-225.

Houben, K. (2011). Overcoming the urge to splurge. The role of inhibitory control in eating behavior. Journal of Behavior Therapy and Experimental Psychiatry, 42 384-388.

Houben, K., \& Jansen, A. (2011). Training inhibitory control. A recipe for resisting sweet temptations. Appetite, 56, 345-349.

Jansen, A., Theunissen, N., Slechten, K., Nederkoorn, C., Boon, B., Mulkens, S., et al. (2003). Overweight children overeat after exposure to food cues. Eating Behaviors, 4, 197-209.

Kleiner, K. D., Gold, M. S., Frost-Pineda, K., Lenz-Brunsman, B., Perri, M. G., \& Jacobs, W. S. (2004). Body mass index and alcohol use. Journal of Addictive Disorders, 23, 105-118.

Logan, G. D., \& Cowan, W. B. (1984). On the ability to inhibit thought and action. A theory of an act of control. Psychological Review, 91, 295-327.

Lowe, M. R. (2003). Self-regulation of energy intake in the prevention and treatment of obesity. Is it feasible? Obesity Research, 11, 44S-59S.

Mather, A. A., Cox, B. J., Enns, M. W., \& Sareen, J. (2008). Association between body weight and personality disorders in a nationally representative sample. Psychosomatic Medicine, 70, 1012-1019.

Mattes, R. D. (1997). Physiological responses to sensory stimulation by food: Nutritional implications. Journal of the American Dietetic Association, 97 406-410.

Nederkoorn, C., Braet, C., Van Eijs, Y., Tanghe, A., \& Jansen, A. (2006). Why obese children cannot resist food. The role of impulsivity. Eating Behaviors, 7, 315-322.

Nederkoorn, C., Havermans, H., Roefs, A., Smulders, F. T. Y., \& Jansen, A. (2006). Impulsivity in obese women. Appetite, 47, 253-256.

Nederkoorn, C., Smulders, F. T. Y., \& Jansen, A. (2000). Cephalic phase responses, craving and food intake in normal subjects. Appetite, 35, 45-55. 
Nederkoorn, C., Van Eijs, Y., \& Jansen, A. (2004). Restrained eaters act on impulse. Personality and Individual Differences, 37, 1651-1658.

Nigg, J. T., Wong, M. M., Martel, M. M., Jester, J. M., Puttler, L. I., Glass, J. M., et al. (2006). Poor response inhibition and a predictor of onset of drinking and drinking problems in adolescents at risk of alcoholism. Journal of the American Academy of Child and Adolescent Psychiatry, 45, 468-475.

Power, M. L., \& Schulkin, J. (2008). Anticipatory physiological regulation in feeding biology. Cephalic phase responses. Appetite, 50, 194-206.

Riggs, N. R., Spruijt-Metz, D., Chou, C. P., \& Pentz, M. A. (2011). Relationships between Executive Cognitive Function and lifetime substance use and obesityrelated behaviors in fourth grade youth. Child Neuropsychology. http:// dx.doi.org/10.1080/09297049.2011.555759.

Scheres, A., Oosterlaan, J., Swanson, J., Morein-Zamir, S., Meiran, N., Schut, H., et al. (2003). The effect of methylphenidate on three forms of response inhibition in boys with AD/HD. Journal of Abnormal Child Psychology, 31 105-120.

Tiffany, S. T., \& Conklin, C. A. (2000). A cognitive processing model of alcohol craving and compulsive alcohol use. Addiction, 95(Suppl. 2), S145-S153.

Tiggemann, M., Kemps, E., \& Parnell, J. (2010). The selective impact of chocolate craving on visuospatial working memory. Appetite, 55, 44-48. van den Hurk, K., van Dommelen, P., van Buuren, S., Verkerk, P. H., \& HiraSing, R. A. (2007). Prevalence of overweight and obesity in the Netherlands in 2003 compared to 1980 and 1997. Archives of Disease in Childhood, 92, 992-995.

Van Winckel, M., \& Van Mil, E. (2001). Wanneer is dik te dik? In C. Braet \& M. Van Winckel (Eds.), Behandelingsstrategieen Bij Kinderen Met Overgewicht (pp. 11-26). Houten: BohnStafleu Van Loghum.

Verbeken, S., Braet, C., Claus, L., Nederkoorn, C., \& Oosterlaan, J. (2009). Childhood obesity and impulsivity. An investigation with performance-based measures. Behaviour Change, 26, 153-167.

Verdejo-García, A., Pérez-Expósito, M., Schmidt-Río-Valle, J., Fernández-Serrano, M. J., Cruz, F., Pérez-García, M., et al. (2010). Selective alterations within executive functions in adolescents with excess weight. Obesity, 18, 1572-1578.

Werthmann, J., Roefs, A., Nederkoorn, C., Mogg, K., Bradley, B., \& Jansen, A. (2011). Can(not) take my eyes of it. Attention bias for food in overweight participants. Health Psychology, 30, 561-569.

Wooley, O. W., Wooley, S. C., \& Woods, W. A. (1975). Effect of calories on appetite for palatable food in obese and nonobese humans. Journal of Comparative and Physiological Psychology, 89, 619-625. 